\title{
CARACTERIZAÇÃO DAS UNIDADES GEOTÉCNICAS DA PORÇÃO LESTE DA REGIÃO METROPOLITANA DE BELO HORIZONTE - MG
}

\author{
Walter dos Reis Junior ${ }^{1}$, Maria Giovana Parizzi ${ }^{2}$ \\ 1 - Cegeo/ICT - Universidade Federal dos Vales do Jequitinhonha e Mucuri. Rodovia MGT 367, km 583, 5000, Alto da Jacuba - Diamantina, MG. \\ CEP: 39100-000. walterdrjunior@yahoo.com.br; \\ 2 - IGC/Universidade Federal de Minas Gerais. Av. Antônio Carlos, 6627, Pampulha - Belo Horizonte, MG. CEP: 31270-901. mgparizzi18@gmail.com
}

Resumo: Este trabalho apresenta a caracterização das unidades geotécnicas da porção oriental da Região Metropolitana de Belo Horizonte. Essa região caracteriza-se por ser um vetor de malha urbana densa e intenso desenvolvimento, além da ocorrência de inúmeras atividades mineradoras. A geologia da área é constituída por rochas granito-gnáissicas dos Complexos Metamórficos Belo Horizonte e Caeté, seccionadas por sistemas de fraturas NW/SE e SW/NE, e rochas metassedimentares e vulcânicas dos Supergrupos Rio das Velhas, São Francisco e Espinhaço, com foliações e acamadamento com mergulhos, predominantemente, para E. A caracterização das litologias descritas teve como principal base bibliográfica o relatório do PDDI/RMBH (Plano Diretor de Desenvolvimento Integrado da Região Metropolitana de Belo Horizonte), que agrupa 10 unidades geotécnicas para toda a Região Metropolitana de Belo Horizonte. Neste trabalho a classificação geotécnica dessas unidades foi realizada a partir da descrição de 114 maciços rochosos localizados em encostas naturais e taludes de corte. Além disso, também foi avaliada a suscetibilidade para ocorrências de processos geodinâmicos. Os resultados contribuíram para a criação de um arcabouço de informações disponíveis sobre as características de unidades geotécnicas da área da RMBH.

Palavras Chave: processos geodinâmicos, comportamento geotécnico

Abstract: CHARACTERIZATION OF THE GEOTECHNICAL UNITS OF THE EASTERN PORTION OF THE METROPOLITAN REGION OF BELO HORIZONTE - MG. This paper presents the characterization of the geotechnical units of the eastern portion of the Metropolitan Region of Belo Horizonte (RMBH). This region is characterized by being a vector of intense development and dense urban mesh, in addition to the occurrence of innumerable mining activities. The geology of the area consists of granite-gneiss rocks of the Belo Horizonte and Caeté Metamorphic Complexes, sectioned by NW/SE and SW/NE fractures systems, and metasedimentary and volcanic rocks of the Rio das Velhas, São Francisco and Espinhaço Supergroups, with foliations and diving, predominantly, to E. The characterization of the described lithologies had as main bibliographic basis the report of the PDDI/RMBH (Master Plan of Integrated Development of the Metropolitan Region of Belo Horizonte), which groups 10 geotechnical units for the entire Metropolitan Region of Belo Horizonte. In this work the geotechnical classification of these units was made from the description of 114 rock masses located on natural and cut slopes. In addition, it was also evaluated the susceptibility to occurrences of geodynamic processes. The results contributed to the creation of a framework of available information on the characteristics of geotechnical units in the RMBH area.

Keywords: geodynamic processes, geotechnical behavior, susceptibility

\section{INTRODUÇÃO}

O planejamento do desenvolvimento urbano nas regiões metropolitanas é de extrema importância, sobretudo no que diz respeito à relação sociedade/meio ambiente. O Plano Diretor de Desenvolvimento Integrado da Região Metropolitana de Belo Horizonte (PDDI/RMBH), publicado em 2011, tem como um de seus resultados o mapa de identificação de tipologias geotécnicas, gerado através de interpretação de unidades geológicas, a partir da qual foram delimitados 10 agrupamentos segundo composições e comportamentos geomecânicos semelhantes (Parizzi et al. 2010; Leite et al. 2010). Entretanto, a metodologia usada para a individualização das unidades geotécnicas foi baseada em experiência de especialistas, não sendo, naquele momento, balizadas por análises de campo e investigações de maior detalhamento.

Foram realizados estudos in situ para a caracterização das unidades geotécnicas, na porção leste da RMBH (Figura 1), propostas pelo PDDI/RMBH (Parizzi et al. 2010). A região analisada é constituída por 20 municípios, perfazendo uma área de aproximadamente $5700 \mathrm{~km}^{2}$ (Figura 1).

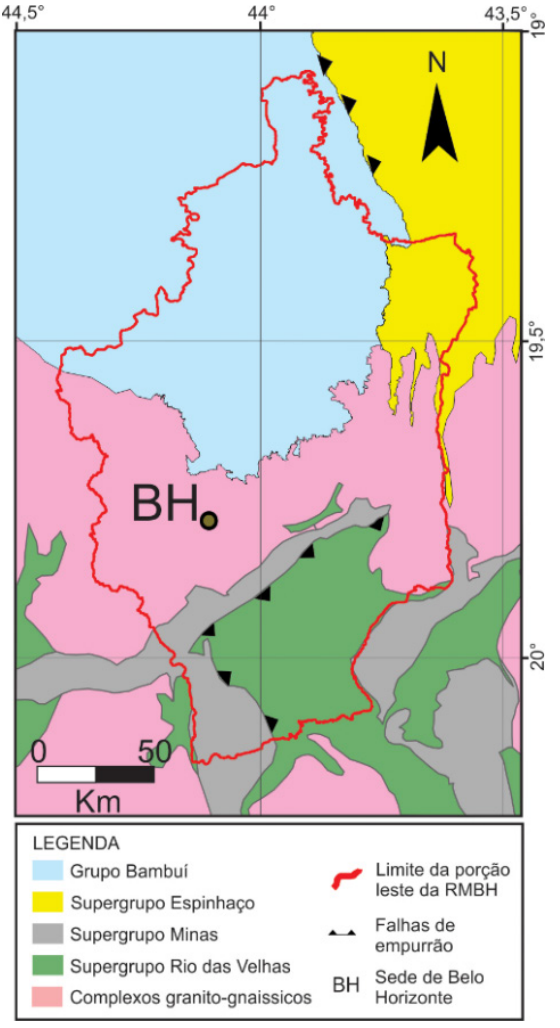

Figura 1. Mapa de unidades geotécnicas da porção leste da $\mathrm{RMBH}$. 


\section{CARACTERIZAÇÃO DO MEIO FíSICO}

O arcabouço geológico da Região Metropolitana de Belo Horizonte constitui-se predominantemente por granitos e gnaisses dos complexos Belo Horizonte e Caeté, sucedidos por uma seqüência greenstone belt meso/neoarqueana (Supergrupo Rio das Velhas), composta por rochas metassedimentares e vulcânicas. Recobrindo partes do embasamento gnáissico e do cinturão metamórfico encontram-se as unidades proterozóicas (Supergrupos Minas e Espinhaço; e Grupo Bambuí), caracterizadas por rochas sedimentares e metassedimentares, como quartzitos, filitos, itabiritos, siltitos e calcários, além de coberturas fanerozóicas (Simmons \& Maxwell 1961, Simmons 1968, Dorr 1969, Dossin et al. 1990, Renger et al. 1994, Baltazar \& Zuchetti 2007, Viana et al. 1998 e Tuller et al. 2010) (Figura 2).

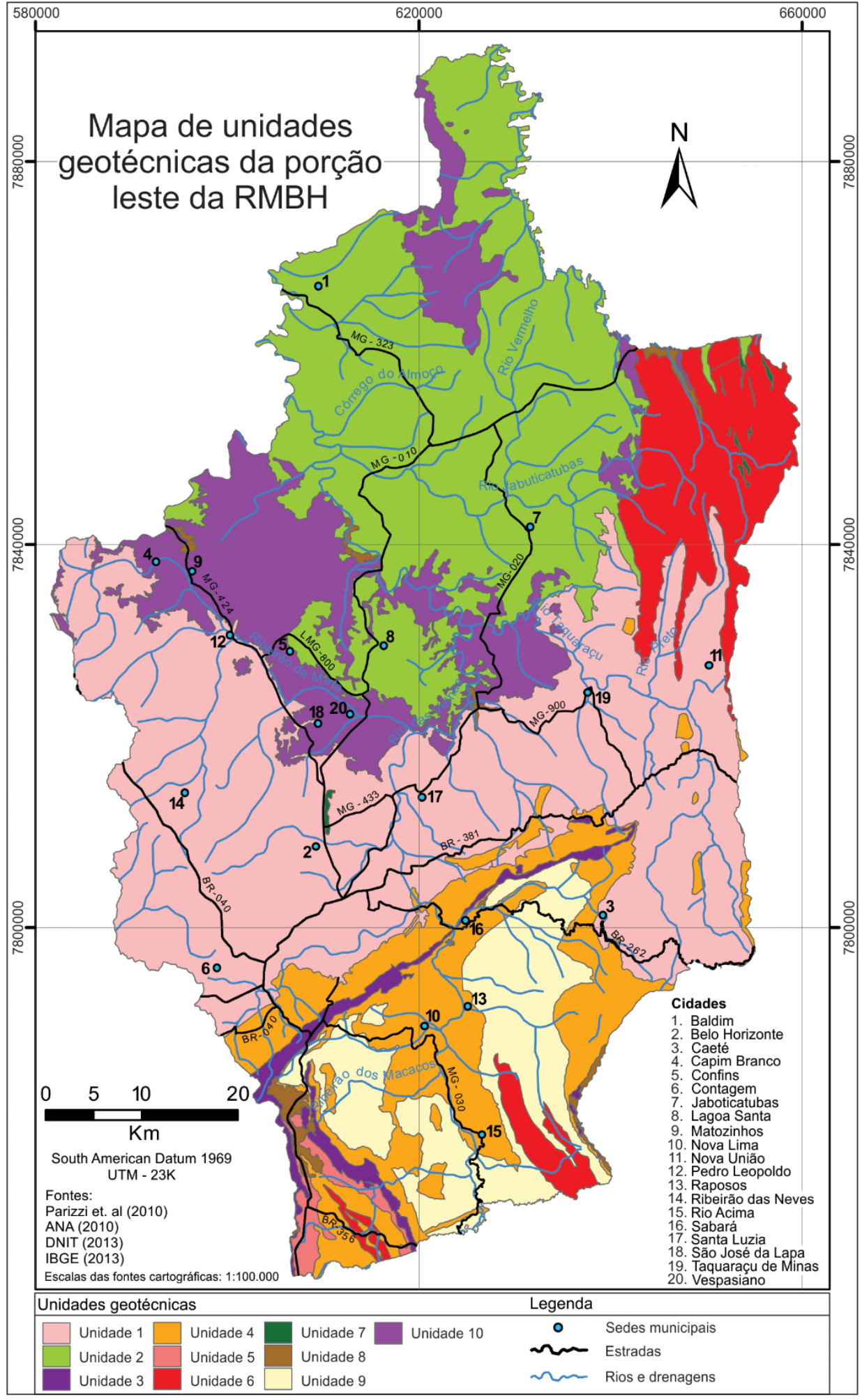

Figura 2. Mapa geológico simplificado da porção leste da RMBH. 
A RMBH apresenta uma fisiografia bastante variada, Silva \& Souza (2009) citam três compartimentos geomorfológicos ocorrendo na RMBH: Quadrilátero Ferrífero, Espinhaço Meridional e Depressão Sanfranciscana.

O Quadrilátero Ferrífero é caracterizado por relevos diversificados, em geral ocorrem ondulações, serras, colinas, vales em $\mathrm{V}$ fechados e vertentes de alta declividade, com altitudes entre 800 e 1300 metros (Silva \& Souza 2009). O Espinhaço Meridional corresponde ao Planalto do Espinhaço Meridional e apresenta altitude média em torno de $1200 \mathrm{~m}$. As formas de relevo resultantes são representadas por cristas, escarpas e vales profundos adaptados às direções tectônicas e estruturais (Saadi 2013). A Depressão Sanfranciscana desenvolveu-se ao longo do Rio São Francisco (CETEC 1983). O relevo associado às rochas do Supergrupo São Francisco, Grupo Bambuí, caracteriza-se, sobretudo, por formas carsticas (Silva \& Souza 2009). As formas fisiográficas desenvolvidas sobre as rochas do Complexo Belo Horizonte são colinas de topos planos a arqueados e altitudes entre 800 e 900m (Boaventura et al. 1977 segundo Baumgratz 1988).

\section{MATERIAIS E MÉTODOS}

Foram caracterizados 114 maciços rochosos, correspondendo a taludes e encostas. Esta etapa foi balizada pelas classificações das propriedades propostas pelo ISRM (1978), que aborda as características das descontinuidades, como orientação, espaçamento, persistência, abertura, rugosidade, preenchimento, percolação de água e estado de alteração, acrescidos de parâmetros como resistência das paredes das descontinuidades e RQD. Também se observou a ocorrência de processos geodinâmicos, como movimentos de massa e feições erosivas.

A resistência à compressão pontual $\left(\sigma_{c}\right)$ dos maciços foi determinada com o auxílio do esclerômetro de Schmidt em rocha in situ. Posteriormente, os índices esclerométricos (HR) obtidos em campo foram tratados através da relação (equação 1) proposta por Katz et al. (2000).

$$
\ln (\sigma c)=0,067 H R+0,792 \quad \text { Equação } 1
$$

Os valores de RQD foram calculados a partir da frequência de descontinuidades por metro linear $(\lambda)$ com o auxílio da equação 2 , proposta por Priest \& Hudson (1976).

$$
R Q D=100 e^{-0,1 \lambda}(0,1 \lambda+1) \quad \text { Equação } 2
$$

Com o auxílio do software ArcGis 9.3, os mapas de unidades geotécnicas em escala 1:100.000 (Parizzi et al. 2010) e o de Solo do Estado de Minas Gerais em escala 1:650.000 (FEAM/CETEC 2010) foram sobrepostos a fim de mensurar a influência dos diversos tipos de solos na composição de cada unidade geotécnica proposta.

Para um melhor entendimento do comportamento mecânico dos maciços influenciado pela presença de estruturas como acamadamento e foliação, compilou-se informações estruturais disponibilizadas em mapeamentos da CODEMIG, em 2005 e 2012, e CPRM, em 2008 e 2009, totalizando 3666 pontos. Estas informações foram tratadas com o software OpenStereo.

\section{CARACTERIZAÇÃO DAS UNIDADES GEOTÉCNICAS}

\section{Unidade Geotécnica 1}

A unidade geotécnica 1 é caracterizada pela ocorrência de rochas granito-gnáissicas, mais comumente granitos, gnaisses e granodioritos. Nessas litologias é observada com freqüência a formação de blocos condicionados pelos sistemas de fraturas, comuns nessa região, o que eleva a suscetibilidade a movimentos de massa, como quedas, rolamentos ou ainda tombamentos. Tais fenômenos dependem da morfologia dos terrenos e do estado de confinamento dos maciços rochosos.

As rochas desta unidade caracterizam-se por elevada resistência mecânica, sobretudo, quando inalteradas e/ou isentas de deformações rúpteis. Estima-se, a partir de dados de campo, valores para resistência a compressão pontual que variam entre 2,2 $\mathrm{MPa}$, para rochas muito intemperizadas e/ou muito fraturadas, e $172 \mathrm{MPa}$, para rochas levemente alteradas/sãs. Também são isotrópicas e homogêneas. Essas características indicam uma elevada qualidade para instalação de fundações, dentre outras intervenções de engenharia civil, além de serem importantes fontes de materiais para construção, como britas.

Solos residuais formados a partir do intemperismo dessas litologias são, em geral, siltoarenosos a argilo-areno siltosos. Esses solos são muito suscetíveis a processos erosivos. Sobretudo, nas porções recobertas por solos pouco desenvolvidos. Cortes e aterros, entre outras ações devem ser desenvolvidos com bastante cuidado, considerando as propriedades dos solos. No tocante das fundações, salienta-se que blocos de granitognaisse podem ocorrer dispersos na massa de solo residual, fator considerado perigoso para instalação de alicerces, devido à capacidade de compactação dos solos sotopostos. As propriedades dos solos sobressaem em relação às das rochas naquelas regiões onde a cobertura pedológica atinge maiores espessuras. Deste modo, o controle dos processos geodinâmicos se limita ao manto de alteração que recobre tais litotipos. 


\section{Unidade Geotécnica 2}

A unidade geotécnica 2 é constituída por rochas pelíticas, predominantemente, siltitos. Nesta região, com frequência, são observados desplacamentos e escorregamentos. Tais processos geodinâmicos são condicionados pela relação angular entre a orientação de estruturas, como foliação e acamadamento, e das vertentes, além de sistemas de fraturas. $\mathrm{Na}$ execução de cortes deve-se observar a atitude das estruturas, para que não haja desconfinamento destas. Contudo, como os terrenos apresentam menores altitudes e relevo com baixa declividade, a necessidade de cortes é reduzida.

Esses litotipos apresentam baixa resistência mecânica, deformando-se com facilidade quando comprimidas. Estima-se valores de resistência à compressão pontual que variam entre 2,2 e 6,9 MPa, mesmo em maciços levemente intemperizados. 0 que resulta em ambientes não favoráveis a execução de grandes construções. São necessários estudos específicos sobre alguns parâmetros dessas litologias, como plasticidade.

Rochas pelíticas são friáveis e muito suscetíveis ao intemperismo, gerando solos siltosos a siltoargilosos, cuja coesão é dependente da quantidade de silte. Materiais mais siltosos tornam-se altamente suscetíveis a erosão e desagregação natural. O predomínio de cambissolos na região, juntamente com as características de solos mais siltosos, justifica os diversos processos erosivos, em diferentes escalas, observados na unidade. Como exemplos podem ser citadas grandes voçorocas descritas na cidade de Lagoa Santa.

\section{Unidade Geotécnica 3}

A unidade geotécnica 3 constitui-se, predominantemente, por itabiritos. Essas rochas são caracterizadas por elevada resistência mecânica, quando maciças e inalteradas, e ao intemperismo, devido a seu conteúdo em óxidos de ferro, como hematita. Ainda podem ser observados litotipos friáveis e com resistência à compressão pontual bastante diminuída, em geral apresentam valores inferiores a $10 \mathrm{MPa}$. A ocorrência de coberturas compostas por cangas e lateritas é comum nessa porção, normalmente, situam-se nas cotas mais superiores, correspondendo aos topos de serras. O manto laterítico apresenta função relevante na manutenção das serras por apresentar elevada resistência mecânica. Ensaios in situ nesses materiais indicam resistência a compressão pontual em torno de $63 \mathrm{MPa}$. Também desempenham um papel importante em áreas de recargas em aqüíferos, devido a sua alta porosidade.

Neste domínio, comumente, são descritos escorregamentos, queda de blocos e empastilhamento, balizados por descontinuidades presentes nas rochas, orientação das encostas, além do grau de alteração. Os solos gerados são ricos em argila e silte, geralmente, caracterizados por baixa suscetibilidade a erosão.

Tendo em vista que a unidade ocorre nas porções de elevadas altitudes e declividades, áreas que correspondem a partes das serras do Curral, Rola Moça e Moeda, o uso urbano não é muito comum. Entretanto, deve-se atentar a ocupações nas adjacências desses terrenos, pois podem se inserir em áreas de influência de movimentos de massa.

\section{Unidade Geotécnica 4}

A unidade geotécnica 4 é constituída, majoritariamente, por rochas metamórficas foliadas, como filitos, xistos e rochas metapelíticas. Esses litotipos apresentam baixa resistência mecânica, devido à abundância de minerais planares, sendo altamente intemperizáveis. Estima-se valores para resistência a compressão pontual entre 2,2 $\mathrm{MPa}$ e $58,9 \mathrm{MPa}$, sendo os maiores determinados em rochas inalteradas, em raras situações. Comumente, são encontradas em elevado estado de alteração.

Observam-se, frequentemente, escorregamentos planares e em cunha, além de queda de blocos, condicionados pela relação angular entre orientação de descontinuidades e vertentes. Salienta-se que processos erosivos são muito comuns na região, sobretudo, condicionados pelas descontinuidades. Esse condicionamento, por vezes, influencia o desplacamento de maciços rochosos.

Mesmo em maciços que não apresentem desconfinamento de estruturas, tombamentos e desplacamentos também podem ser desencadeados, desde que a base de maciços confinados esteja desestabilizada, fazendo que as descontinuidades em sentido contrário as encostas ou cortes, funcionem como delimitadores de blocos.

Os solos residuais dessas rochas, em geral, são silto-argilosos. Devido sua maior coesão apresenta suscetibilidade mediana a erosão.

O conjunto de descontinuidades desses maciços apresenta grande relevância em seu comportamento geomecânico. Em intervenções antrópicas devem-se evitar o desconfinamento dos maciços, a fim de manter sua estabilidade, seja para instalação de fundações ou cortes de estradas. Além de desconfinamento há a possibilidade da atuação de processos erosivos. O material gerado durante cortes, não apresenta boa função como aterros, devido às baixas coesão e compactação.

\section{Unidade Geotécnica 5}

A unidade geotécnica 5 constitui-se de dolomitos. Essas rochas se caracterizam por elevada resistência 
mecânica, o que confere uma boa qualidade para a sua utilização como material de construção. Porém, são altamente suscetíveis ao intemperismo e apresenta alto grau de dissolução, culminando em processos de carstificação, elevando a suscetibilidade a abatimentos e colapsos.

Suas camadas apresentam ângulos de mergulho mais intensos e ocorrem associados a relevos mais elevados e íngremes, adjacentes aos itabiritos da unidade 3. Nessas rochas podem ser gerados blocos condicionados por descontinuidades e, menos comumente, quando foliadas podem ser desencadeados escorregamentos.

Sua cobertura pedológica caracteriza-se por solos argilosos a silto-argilosos, pouco espessos. Devido ao seu baixo desenvolvimento pedogenético é de fácil erosão.

\section{Unidade Geotécnica 6}

A unidade geotécnica 6 é composta, sobretudo, por quartzitos. Os litotipos caracterizam-se por elevada resistência mecânica e ao intemperismo. Ensaios in situ apontam resistência a compressão pontual em torno de $77 \mathrm{MPa}$, quando inalteradas e confinadas. Devido a tais propriedades essas rochas têm importante função para fundações.

Nas porções mais a norte neste zoneamento, nas proximidades da Serra do Cipó, observam-se quedas de blocos e tombamentos condicionados por diversos sistemas de fraturas. Mas nas áreas a sul (nos municípios de Rio Acima, Nova Lima e Raposos), registra-se a ocorrência de deslizamentos, influenciados pela foliação dessas litologias. Os processos geodinâmicos que atuam nessa unidade são controlados, principalmente, pelas descontinuidades que seccionam os maciços rochosos. Portanto, cortes mal planejados podem desconfinar maciços, gerando blocos e condicionando movimentos de massa.

Em geral, nas regiões de ocorrência de quartzitos os solos são muito pouco espessos e arenosos. No entanto, nas porções de ocorrência de metaruditos, o solo gerado pelo intemperismo é caracterizado por grande variedade granulométrica. Devido à baixa coesão, esses solos residuais são altamente suscetíveis a processos erosivos.

\section{Unidade Geotécnica 7}

$\mathrm{Na}$ unidade geotécnica 7 ocorrem rochas metaultramáficas, que intrudem o Complexo Belo Horizonte e metadiabásios que ocorrem em soleiras e diques máficos, intrudindo rochas do Supergrupo Espinhaço.

Essas litologias apresentam elevada resistência mecânica, quando pouco intemperizadas. Porém, são altamente suscetíveis ao intemperismo, sendo raras as ocorrências de maciços pouco intemperizados. Em geral, são rochas muito fraturadas. Mecanicamente apresentam características muito semelhantes aos gnaisses que ocorrem na unidade geotécnica 1 . Apresentam importante função em fundações e materiais de construção, quando essas litologias encontram-se pouco alteradas ou ainda inalteradas.

Processos geodinâmicos também são restritos, ocorrendo em maior intensidade queda de blocos condicionados às fraturas.

Como produtos de sua alteração são gerados solos argilosos, bem coesos. Isso permite uma maior estabilidade frente a processos erosivos e escorregamentos.

\section{Unidade Geotécnica 8}

A unidade geotécnica 8 corresponde as coberturas detrito-lateríticas e depósitos aluvionares, aluviais e coluviais. Ocorrem nesse agrupamento lateritas e diversos depósitos de areia, argila, silte e cascalhos. Esses materiais, em geral, apresentam-se inconsolidados. São caracterizados por elevada suscetibilidade a erosão e movimentos de massa, sendo altamente plásticos, quando constituído por argilas. Nas porções de ocorrência de cangas e lateritas, a resistência a processos erosivos e intemperismo se eleva.

Ocorrem, geralmente, em planícies e encostas. Caracterizando lugares suscetíveis a alagamentos e inundações. Essas áreas não são aconselháveis para instalações urbanas, visto que diversos outros processos geodinâmicos pode se desenvolver. Como por exemplo, rastejos em depósitos coluvionares, queda de blocos em porções lateríticas fraturadas ou ainda recalque nas regiões mais plásticas, constituídas por argilas.

\section{Unidade Geotécnica 9}

A unidade geotécnica 9 caracteriza-se pela ocorrência de metagrauvacas e metarenitos. Embora o comportamento dessas litologias seja semelhante ao de rochas de outras unidades geotécnicas, como os quartzitos, rochas metamórficas foliadas e pelíticas, estas estão associadas a rochas vulcanossedimentares em elevado estado de intemperismo. A composição dessas rochas influencia sua resistência mecânica, de acordo com a proporção de quartzo. As porções mais quartzosas apresentam resistências mais elevadas. Caracterizam-se por foliações bem desenvolvidas, que condicionam diversos processos geodinâmicos.

Os solos gerados pelo intemperismo dessas rochas são areno-siltosos a silto-argilosos. A variação no teor de areia nesses solos pode influenciar sua suscetibilidade à erosão, fazendo com que haja modificações na coesão dessas coberturas. Devido ao 
elevado estado de alteração desses maciços, comumente, observa-se o desenvolvimento de processos erosivos.

Para o uso urbano dessas áreas ressalta-se a importância do planejamento para o manejo desses terrenos. Do ponto de vista das descontinuidades, é necessário atentar-se para não desconfinar essas estruturas, fazendo com que sejam desencadeados escorregamentos. Para a instalação de fundações essas áreas são boas, devido a elevada resistência a compressão em algumas porções, entretanto, por estarem muito alteradas, essa característica só será aproveitada em maiores profundidades, assim como nas porções mais pelíticas e foliadas.

\section{Unidade Geotécnica 10}

Na unidade geotécnica 10 ocorrem calcários. Essas rochas apresentam elevada resistência mecânica, quando inalteradas. Foram estimados valores entre 72 e $141 \mathrm{MPa}$ para resistência a compressão pontual. Uma característica importante é o alto grau de dissolução dessas litologias, o que pode formar dutos subterrâneos, caracterizando a área com um elevado potencial aqüífero. Portanto, medidas de preservação e controle de resíduos devem ser adotadas, a fim de proteger os recursos hidrogeológicos de contaminação. Porém, com o processo de carstificação também são geradas outras feições de dissolução, como sulcos, fendas, sumidouros, cavernas e dolinas. Esses fenômenos subsuperficiais podem deflagrar abatimentos de terra, colapsos e subsidências. Além disso, podem representar um grande problema para fundações, embora essas rochas apresentem alta resistência mecânica.

Planos de acamamento e foliações e sistemas de fraturas podem controlar a formação de blocos e rupturas, intensificando movimentos de massa. Entretanto é válido salientar que nessa unidade ocorrem terrenos de relevos suaves e topograficamente mais baixos, reduzindo a suscetibilidade à esses fenômenos.

Os solos residuais gerados são argilosos a siltoargilosos, o que confere uma baixa suscetibilidade a processos erosivos. Seu manto pedológico é constituído por solos mais desenvolvidos.

As tabelas 1 e 2 sintetizam algumas características das unidades geotécnicas, como geologia, pedologia, processos geodinâmicos e seus condicionantes.

Tabela 1 Área de abrangência, geologia e pedologias das unidades geotécnicas.

\begin{tabular}{|c|c|c|c|c|}
\hline $\begin{array}{l}\text { Unidade } \\
\text { geotécnica }\end{array}$ & $\begin{array}{l}\text { Área } \\
\left(\mathrm{km}^{2}\right)\end{array}$ & $\begin{array}{l}\text { Litologias } \\
\text { dominantes }\end{array}$ & Unidade geológica & Solos \\
\hline 1 & $\begin{array}{c}1938 \\
(33,9 \%)\end{array}$ & $\begin{array}{l}\text { Rochas granito- } \\
\text { gnáissicas }\end{array}$ & $\begin{array}{c}\text { Complexos Belo Horizonte e } \\
\text { Caeté }\end{array}$ & $\begin{array}{l}\text { Silto-arenosos e argilos-arenos } \\
\text { siltosos } \\
\text { Latossolos e argissolos (86,5\%) } \\
\text { Argissolos }(12,4 \%)\end{array}$ \\
\hline 2 & $\begin{array}{l}1431 \\
(25 \%)\end{array}$ & Siltitos & $\begin{array}{c}\text { Fm. Serra de Santa Helena - } \\
\text { Gr. Bambuí }\end{array}$ & $\begin{array}{c}\text { Silto-argilosos } \\
\text { Cambissolos (84\%) } \\
\text { Latossolos e argissolos (16\%) }\end{array}$ \\
\hline 3 & $80(1,4 \%)$ & Itabiritos & Grupo Itabira & Neossolos litólicos (96\%) \\
\hline 4 & $\begin{array}{c}625 \\
(10,9 \%)\end{array}$ & $\begin{array}{l}\text { Rochas } \\
\text { metamórficas } \\
\text { foliadas }\end{array}$ & $\begin{array}{c}\text { Grupos Caraça e Piracicaba e } \\
\text { Fm. Cambotas }\end{array}$ & $\begin{array}{c}\text { Silto-argilosos } \\
\text { Neossolos litólicos (46\%) } \\
\text { Cambissolos }(42 \%)\end{array}$ \\
\hline 5 & $41(0,7 \%)$ & Dolomitos & Grupo Itabira & $\begin{array}{l}\text { Argilosos a silto-argilosos } \\
\text { Neossolos litólicos (100\%) }\end{array}$ \\
\hline 6 & $\begin{array}{c}416 \\
(7,3 \%)\end{array}$ & Quartzitos & $\begin{array}{l}\text { Fm. Tabuões, Sopa- } \\
\text { Brumadinho e Galho do Miguel }\end{array}$ & $\begin{array}{c}\text { Arenosos } \\
\text { Neossolos litólicos }(81,3 \%) \\
\text { Cambissolos }(12,2 \%) \\
\text { Latossolos }(6,5 \%)\end{array}$ \\
\hline 7 & $7(0,1 \%)$ & $\begin{array}{l}\text { Rochas } \\
\text { metaultramáficas e } \\
\text { metadianásios }\end{array}$ & Instrusões de soleiras e diques & $\begin{array}{c}\text { Argilosos } \\
\text { Latossolos e argissolos }(99,7 \%) \\
\text { Neossolos litólicos }(0,3 \%)\end{array}$ \\
\hline 8 & $42(0,7 \%)$ & $\begin{array}{l}\text { Lateritas e diversos } \\
\text { depósitos de } \\
\text { sedimentos }\end{array}$ & $\begin{array}{c}\text { Coberturas detrito-lateríticas e } \\
\text { depósitos aluvionares, aluvais } \\
\text { e coluviais }\end{array}$ & - \\
\hline 9 & $\begin{array}{c}430 \\
(7,5 \%)\end{array}$ & $\begin{array}{l}\text { Metagrauvas e } \\
\text { metarenitos }\end{array}$ & Grupo Nova Lima & $\begin{array}{l}\text { Areno-siltosos e silto-argilosos } \\
\text { Cambissolos }(77,4 \%) \\
\text { Neossolos litólicos }(22,6 \%)\end{array}$ \\
\hline 10 & $\begin{array}{c}707 \\
(12,4 \%)\end{array}$ & Calcários & $\begin{array}{l}\text { Fm. Sete Lagoas e Lagoa do } \\
\text { Jacaré }\end{array}$ & $\begin{array}{l}\text { Argilosos a silto-argilosos } \\
\text { Cambissolos (30,7\%) } \\
\text { Latossolos e argissolos }(69,3 \%)\end{array}$ \\
\hline
\end{tabular}


Tabela 2. Processos geodinâmicos e seus condicionantes associados às unidades geotécnicas.

\begin{tabular}{|c|c|c|c|}
\hline $\begin{array}{l}\text { Unidade } \\
\text { geotécnica }\end{array}$ & Litologia & Processos geodinâmicos & Condicionantes \\
\hline 1 & $\begin{array}{l}\text { Rochas granito- } \\
\text { gnáissicas }\end{array}$ & $\begin{array}{l}\text { Quedas, rolamentos e } \\
\text { tombamentos de blocos }\end{array}$ & $\begin{array}{c}\text { Morfologia de terrenos e taludes; } \\
\text { Sistemas de fraturas }(9 / 73,56 / 82,308 / 62) \text { e falhamentos. }\end{array}$ \\
\hline 2 & Siltitos & $\begin{array}{l}\text { Desplacamentos e } \\
\text { escorregamentos }\end{array}$ & $\begin{array}{l}\text { Relação angular entre orientação das estruturas (90/17) e } \\
\text { das vertentes; } \\
\text { Sistemas de fraturas (300/08, 4/88, 212/85). }\end{array}$ \\
\hline 3 & Itabiritos & $\begin{array}{l}\text { Escorregamentos, queda } \\
\text { de blocos e } \\
\text { empastilhamento }\end{array}$ & $\begin{array}{l}\text { Orientação das encostas; } \\
\text { Atitude de foliações e acamamentos }\left({ }^{*}\right) \\
\text { Sistemas de fraturas }(231 / 77,36 / 71) \\
\text { Grau de alteração. }\end{array}$ \\
\hline 4 & $\begin{array}{l}\text { Rochas } \\
\text { metamórficas } \\
\text { foliadas }\end{array}$ & $\begin{array}{l}\text { Escorregamentos planar } \\
\text { e em cunha, } \\
\text { desplacamentos e queda } \\
\text { de blocos }\end{array}$ & $\begin{array}{c}\text { Orientação das encostas; } \\
\text { Atitude de foliações e acamamentos }\left({ }^{*}\right) \\
\text { Sistemas de fraturas }(209 / 87,350 / 83,175 / 82) \text {. }\end{array}$ \\
\hline 5 & Dolomitos & $\begin{array}{l}\text { Formação de blocos e } \\
\text { menos comumente } \\
\text { escorregamentos }\end{array}$ & $\begin{array}{c}\text { Foliações e acamamentos }(83 / 53) ; \\
\text { Sistemas de fraturas }\left({ }^{*}\right) ;\end{array}$ \\
\hline 6 & Quartzitos & $\begin{array}{l}\text { Queda e tombamentos } \\
\text { de blocos (norte) e } \\
\text { escorregamentos (sul) }\end{array}$ & $\begin{array}{l}\text { Acamamento/foliação (77/33) e sistemas de fraturas } \\
(100 / 54,313 / 43) \text { - porção norte; } \\
\text { Orientação das descontinuidades }\left(^{*}\right) \text { dessas litologias e } \\
\text { também associadas às rochas da sequencia - porção sul. }\end{array}$ \\
\hline 7 & $\begin{array}{l}\text { Rochas } \\
\text { metaultramáficas e } \\
\text { metadianásios }\end{array}$ & Queda de blocos & $\begin{array}{l}\text { Morfologia de terrenos e taludes; } \\
\text { Sistemas de fraturas (similares à unidade } 1 \text { ) e falhamentos. }\end{array}$ \\
\hline 8 & $\begin{array}{l}\text { Lateritas e diversos } \\
\text { depósitos de } \\
\text { sedimentos }\end{array}$ & $\begin{array}{l}\text { Movimentos de massa } \\
\text { (rastejos) }\end{array}$ & $\begin{array}{l}\text { Elevada suscetibilidade a erosao e movimentos de massa, } \\
\text { sendo altamente plásticos, quando constituído por argilas. }\end{array}$ \\
\hline 9 & $\begin{array}{l}\text { Metagrauvas e } \\
\text { metarenitos }\end{array}$ & $\begin{array}{l}\text { Queda de blocos e } \\
\text { escorregamentos }\end{array}$ & $\begin{array}{l}\text { Morfologia dos terrenos e taludes; } \\
\text { Orientação de acamamentos e foliações }\left({ }^{*}\right) \text { e sistemas de } \\
\text { fraturas. }\end{array}$ \\
\hline 10 & Calcários & $\begin{array}{l}\text { Formação de blocos, } \\
\text { abatimentos e colapsos }\end{array}$ & $\begin{array}{c}\text { Orientação das vertentes; } \\
\text { Atitude de acamamento/foliação (87/08); } \\
\text { Sistemas de fraturas (230/88, 180/50, 25/75); } \\
\text { Elevado grau de dissolução (risco de abatimentos e } \\
\text { colapsos). }\end{array}$ \\
\hline & & $\begin{array}{l}\text { rochas do Quadrilát } \\
73 / 36,104 / 47,1\end{array}$ & $\begin{array}{l}\text { rífero, orientam-se, preferencialmente para leste }(83 / 53 \text {, } \\
\text { e } 146 / 47) \text {. }\end{array}$ \\
\hline
\end{tabular}

\section{CONSIDERAÇÕES FINAIS}

Com o crescimento dos grandes centros urbanos, sobretudo nas regiões metropolitanas, é crescente a preocupação com o planejamento do desenvolvimento. Assim, os aspectos que influenciam a dinâmica superficial são de extrema importância, visto que a relação entre as entidades geológicas, seu arcabouço estrutural, morfologia do relevo e atividade antrópica associam-se gerando riscos a utilização de certas áreas, podendo desencadear diversos processos geodinâmicos.

Através de técnicas de caracterização e classificação geomecânica de maciços rochosos e geoprocessamento, a cartografia geotécnica proposta no PDDI foi refinada, embasando uma discussão um pouco mais aprofundada no que tange o comportamento dos materiais geológicos e sua contribuição na deflagração de processos geodinâmicos, como movimentos de massa.

Quanto às características geomecânicas das rochas que ocorrem na porção leste da Região Metropolitana de Belo Horizonte, as análises evidenciaram diversos aspectos que influenciam o comportamento mecânico das litologias aflorantes. Destaca-se a variação da resistência à compressão pontual dos diversos litotipos em detrimento à composição, natureza e grau de alteração dos mesmos. O comportamento das descontinuidades, como foliações, acamamentos e sistemas de fraturas devem ser melhor compreendidos, visto que são condicionantes importantes no desencadeamento desses fenômenos. Os mergulhos de foliações e acamamentos são, preferencialmente, para leste e os dois sistemas de fraturas, que seccionam as rochas dos complexos metamórficos cristalinos, orientam-se para NW/SE e SW/NE.

Ressalta-se a importância do emprego de ferramentas de geoprocessamento em análises do meio físico. Através destas é possível manipular e associar diversos aspectos pertinentes a caracterização e compreensão de fenômenos relacionados à dinâmica superficial. Entretanto, a disponibilidade de materiais cartográficos em escalas maiores ainda é bastante restrita.

Tendo em vista a necessidade cada vez maior de informações mais detalhadas, para a elaboração de cartas e mapas temáticos, no que tange o 
zoneamento urbano, potencialidades e riscos, trabalhos como este e o elaborado durante o PDDI (Parizzi et al. 2010) servem como balizadores para futuros estudos.

\section{REFERÊNCIAS BIBLIOGRÁFICAS}

Baltazar, O.F., Zucchetti, M., 2007. Lithofacies associations and structural evolution of the Archean Rio das Velhas greenstone belt, Quadrilatero Ferrifero, Brazil: A review of the setting of gold deposits. Ore Geology Reviews. 32:471-499.

Baumgratz, S.S. 1988. O planejamento urbano de Belo Horizonte e seus problemas geomorfológicos. Geografia, 13(25): 117-131.

Boaventura, R.S.; Moreira, C.V.R.; Boaventura, F.M.C. 1977. Mapa Geomorfológico: Folha Belo Horizonte. In Projeto Radar Minas Gerais, Secretaria de Estado de Ciência e Tecnologia. Instituto de Geociências Aplicadas (IGA), escala 1:500.000.

Centro Tecnológico de Minas Gerais (CETEC). 1983. Diagnóstico ambiental do estado de Minas Gerais. Belo Horizonte. Série de publicações técnicas, $10.158 \mathrm{p}$

Dorr, J.V. 1969. Physiographic, stratigraphic and structural development of the Quadrilátero Ferrífero, Minas Gerais. USGS Professional Paper 614-A, $110 \mathrm{p}$.

Dossin, I.A., Dossin, T.M. \& Chaves, M.L.S.C. 1990 Compartimentação Estratigráfica do Supergrupo Espinhaco em Minas Gerais - os Grupos Diamantina e Conselheiro Mata. Revista Brasileira de Geociências, 20(1-

4): $178-186$.

ISRM. 1978. Suggested mothods for the quantitative description of discontinuities. In Rock Mechanics. Internacional Journal of Rock Mechanics Science and Geomechanics. Abstract, 15: 319368.

Katz O, Reches Z \& Roegiers J.C. 2000. Evaluation of mechanical rock properties using a Schmidt hammer. In International Journal Rock Mech. Sci., 37:723-728.

Leite, D. V. B; Magalhães, D. M. de; Moura, A. C. M. \& Parizzi, M. G. 2010. Analise de expansão urbana através de classificação de imagens e análise de multicritérios como apoio ao planejamento urbano municipal - estudo de caso de Ribeirão das Neves - MG. In SBC, Congresso Brasileiro de Cartografia, Aracajú, XXIV, Anais, 9p.

Renger, F. E. ; Noce, C. M.; Romano, A. W. ; Machado, N. 1994. Evolução sedimentar do Supergrupo Minas: 500 Ma de registro Geológico no Quadrilátero Ferrífero, Minas Gerais, Brasil. Belo Horizonte, Geonomos, (2)1:1-11.

Saadi, A. 2013. A geomorfologia da Serra do Espinhaço em Minas Gerais e de suas margens. Belo Horizonte. Geonomos 3(1): 4163.

Silva, V.C.B. \& Souza, C.J.O. 2009. A contribuição didática do trabalho de campo na compreensão da paisagem da Região Metropolitana de Belo Horizonte e entorno a partir da cartografia e dos vestígios sociais e físicos. In ENPEG. Porto Alegre, X, Trabalho Completos. $14 \mathrm{p}$.

Simmons, G.C. \& Maxwell, C.H. 1961. Grupo Tamanduá da Série Rio das Velhas. Rio de Janeiro, DNPM/DGM. Boletim 221, 30p.

Simmons, G.C. 1968. Geology and mineral resources of the Barão de Cocais area, Minas Gerais, Brazil. U.S. Geol.Survey Prof. Paper 341-H, p. 1-48.

Parizzi, M.G; Moura, A.C.M; Memória, E. \& Magalhães, D.M. 2010. Mapa de unidades geotécnicas da Região Metropolitana de Belo Horizonte. RMBH. 21p. In Programa Diretor de Desenvolvimento Integrado da $\mathrm{RMBH}$ : Relatório de Geoprocessamento.

Priest S.D. \& Hudson J.A. 1976. Discontinuity spacings in rock. Int. J. Rock Mech. Min. Sci. \& Geomech. Abstr., 13:135-148.

Tuller, M.P. 2010. Capitulo 2 - Aspectos Fisiográficos, Hidrografia, Clima e Vegetação. p. 21-24. In: Tuller, M.P; Ribeiro, J.H; Signorelli, N; Feboli, W.L. \& Pinho J.M.M. (orgs). 2010. Projeto Sete Lagoas-Abaeté, Estado de Minas Gerais: texto explicativo. Belo Horizonte. CPRM-BH.

Viana, H.S; Tavares, V.P. \& Kohler, H.C. 1998. Síntese da geologia, recursos minerais e geomorfologia. 17 p. in CPRM. 1998. APA Carste de Lagoa Santa: Volume I - Meio Físico. Belo Horizonte. $301 \mathrm{p}$. 